\title{
Analisis Desk Research Kebijakan Technology Transfer Office Sebagai Solusi Hambatan Teknologi Transfer di Lembaga Litbang Indonesia
}

\section{OPEN ACCESS}

Citation: Wisnu Pradana, A., Yuka Asmara, A., Triyono, B., Jayanthi, R., Dinaseviani, A., Purwadi, \& Nashihuddin, W. (2021). Analisis Desk Research Kebijakan Technology Transfer Office Sebagai Solusi Hambatan Teknologi Office Sebagai Solusi Hambatan Teknologi Matra Pembaruan. 5(1), 1-12

Received: February 4, 2021 Accepted: April 30, 2021 Published: May 31, 2021

\section{(c) The Author(s)}

\section{cc) (i) (2) (2)}

This work is licensed under a Creative Commons Attribution-NonCommerciaShareAlike 4.0 International License.
Keywords: te chnology transfer office, technology transfer, technology transfer policy, research and development, commercialization.
Kata Kunci: te c h n o l o gy transfer office, teknologi transfer, kebijakan transfer teknologi, penelitian dan pengembangan, komersialisasi

\author{
Aditya Wisnu Pradana (iD) ${ }_{1}$,Anugerah Yuka Asmara (iD) 2 , Budi Triyono ${ }^{(i D}{ }_{3}$, Ria \\ Jayanthi ${ }^{\text {ID }}{ }^{4}$, Anggini Dinaseviani ${ }^{5}$, Purwadi ${ }^{\text {iD }} 6$, Wahid Nashihuddin (iD 7 \\ 1,2,3,4,5,6,7 Lembaga Ilmu Pengetahuan Indonesia
}

Jl. Jend. Gatot Subroto No.10 Jakarta 12710

$\square$ adityawisnupradana91@gmail.com

\begin{abstract}
The government-owned research and development institutions (lembaga litbang) has been established for a long time; units under the ministries, universities, or an independent institution structure called the Non-Ministry Government Institutions in the field of Research and Technology (LPNK Ristek). However, the long course of LPNK Ristek is measured to be not in line with the output of the research and development (R\&D) due to its minimal contribution in commercializing the results to its users. This study aims to provide a depth understanding of the form of policy design as the result of low commercialization of R\&D results in Indonesia along with existing technology transfer policies. This study also proposes new policy alternatives, namely the Technology Transfer Office (TTO) to improve the existing policy. The approach of this study is qualitative with the desk research method. The data sources were published in the period 1996 to 2020. The results of this study found that there were three obstacles to technology transfer in Indonesian R\&D institutions, namely the lack of funding, limited quality and quantity of human resources, and a rigid institutional structure that hindered the function of technology transfer. This study also recommends the TTO policy as an alternative technology transfer policy with four main instruments, namely (1) the government activities involved, (2) the structure of the delivery system either directly or indirectly, (3) the degree of centralization, and (4) the degree of automation with funding mechanisms, human resources, and institutions in the form of a Public Service Agency $(B L U)$.
\end{abstract}

\begin{abstract}
Abstrak: Kiprah lembaga penelitian dan pengembangan milik pemerintah sudah ada sejak lama, baik unit yang berada di bawah kementerian atau perguruan tinggi maupun yang independen dalam struktur Lembaga Pemerintah Non Kementerian bidang Riset dan Teknologi (LPNK Ristek). Namun, panjangnya eksistensi LPNK Ristek dinilai tidak sejalan dengan output hasil litbang karena minimnya kontribusi LPNK Ristek dalam melakukan hilirisasi hasil kegiatan penelitian dan pengembangan (litbang) ke para pengguna. Studi ini berupaya memberikan pemahaman mengenai bentuk desain kebijakan yang berangkat dari isu tersebut dan mengusulkan alternatif kebijakan baru, yakni Technology Transfer Office (TTO). Pendekatan studi ini adalah kualitatif dengan metode desk research. Sumber data tersebut dipublikasikan dalam rentang waktu tahun 1996 hingga tahun 2020. Hasil dari studi ini menemukan ada tiga hambatan transfer teknologi di lembaga litbang Indonesia yakni minimnya pendanaan, terbatasnya kualitas dan kuantitas SDM, serta struktur kelembagaan yang kaku dan menghambat fungsi transfer teknologi. Studi ini merekomendasikan kebijakan TTO sebagai alternatif kebijakan transfer teknologi dengan empat instrumen utamanya yakni (1) dari aktivitas pemerintah yang terlibat, (2) struktur sistem penyampaian baik langsung atau tidak langsung, (3) derajat sentralisasi, dan (4) derajat automisasi dengan mekanisme pendanaan, SDM, dan kelembagaan berupa Badan Layanan Umum (BLU).
\end{abstract}




\section{Pendahuluan}

Lembaga penelitian dan pengembangan (litbang) pemerintah telah eksis sejak era Orde lama hingga saat ini dalam berbagai versi perubahannya, serta telah banyak hasil-hasil penelitian yang menjadi keluaran (Asmara, 2016; Oktaviyanti et al., 2013). Sayangnya, berbagai hasil penelitian ini belum dapat dihilirisasi melalui teknologi transfer dengan baik. Banyak persoalan yang menghambatnya mulai dari pendanaan, sumber daya manusia (SDM) hingga kelembagaan. Persoalan-persoalan yang menghambat tersebut tentu saja menarik untuk dicermati dan dikaji. Oleh karena itu, penelitian atau kajian ini berusaha untuk menjabarkannya sekaligus mencari alternatif solusi kebijakan teknologi transfer yang lebih baik.

Sejatinya perjalanan panjang lembaga litbang milik pemerintah sudah dimulai sejak era Orde Lama, tepatnya dengan didirikannya Majelis Ilmu Pengetahuan Indonesia (MIPI) pada 1965 (Asmara, 2016). Namun, di era Orde Baru 1967, pemerintah membubarkan MIPI lalu membentuk tiga lembaga penelitian dan pengembangan yaitu Lembaga Ilmu Pengetahuan Indonesia (LIPI), Badan Tenaga Nuklir Nasional (BATAN), dan Lembaga Penerbangan dan Antariksa Nasional (LAPAN). Lalu di tahun 1978 dibentuk Badan Pengkajian dan Penerapan Teknologi (BPPT) tepat pada saat B.J. Habibie menjabat sebagai Menteri Negara Riset dan Teknologi (Oktaviyanti et al., 2013).

Keempat lembaga litbang publik, yaitu LIPI, BPPT, BATAN dan LAPAN merupakan lembaga litbang independen yang terpisah dari struktur lembaga litbang di bawah Kementerian Pusat atau bukan bagian dari lembaga penelitian di Perguruan Tinggi Negeri (Asmara, 2016). Secara hirarki garis komando, keberadaan lembagalembaga litbang tersebut bersifat independen langsung di bawah Presiden RI dan dikoordinasikan oleh Kementerian Riset dan Teknologi/Badan Riset dan Inovasi Nasional (Kemenristek/BRIN). Karena sifat dan nomenklatur inilah, keempat lembaga litbang tersebut dikenal dengan Lembaga Pemerintah Non-Kementerian bidang Riset dan Teknologi (LNPK Ristek).

Tercatat berbagai kegiatan litbang yang dilakukan keempat LNPK Ristek meningkat setiap tahunnya baik dari segi kuantitas keluaran (output) litbang maupun dari sisi kualitas keluaran yang dihasilkan. Adapun bentuk keluaran yang paling banyak berupa publikasi ilmiah, seperti laporan penelitian, artikel jurnal ilmiah, prosiding, buku, kertas kerja (working papers) hingga ringkasan kebijakan (policy brief) yang umumnya bersifat tataran teoritis. Namun besarnya kuantitas keluaran hasil litbang yang dihasilkan LPNK Ristek dinilai belum bisa mengakomodir kebutuhan para pengguna secara langsung (Lakitan, Hidayat, \& Herlinda, 2012; Soedarsono, 2004).

Tidak dipungkiri, keberadaan keempat LPNK Ristek menjadi motor penggerak sumber daya ilmu pengetahuan dan teknologi nasional dengan melakukan fungsinya yaitu melakukan kegiatan litbang pada ilmu-ilmu penelitian dasar maupun penelitian terapan, peningkatan teknologi, hingga komersialisasi teknologi (Asmara, 2016; Zuhal, 2000). Di sisi lain, persoalan sumber daya manusia (SDM) di LPNK Ristek juga masih menjalankan kepentingan pribadi dari peneliti dan perekayasa. World Bank dan Kementerian Ristekdikti (2017) mengemukakan bahwa jumlah hasil penelitian yang mampu dipatenkan dalam LPNK masih relatif sedikit. Hal ini disebabkan minimnya kesadaran peneliti untuk mematenkan dan melakukan penelitian berdasarkan kebutuhan pasar (industri dan pengguna). Bahkan, beberapa peneliti masih melakukan riset karena ketertarikan pribadi, sehingga tidak dikomersialkan.

Minimnya kontribusi LPNK Ristek dalam menunjang pembangunan nasional menjadi pekerjaan bagi pemerintah setiap tahun, dan hal ini tidak terlepas dari upaya dan bentuk transfer teknologi yang dilakukan oleh lembaga litbang tersebut. Salah satu indikasi dasar akan produktivitas di bidang iptek yakni publikasi ilmiah. Menurut Gerintya (2017), sepanjang tahun 1996-2016, jumlah publikasi terindeks global Indonesia mencapai 54.146. Bila dibandingkan dengan Singapura, Thailand, dan Malaysia, peringkat Indonesia masih jauh berada di bawah ketiga negara ASEAN tersebut. Pada tahun 2016, di tingkat dunia, Indonesia menempati peringkat 45 untuk publikasi internasional. Di Kawasan Asia, Indonesia berada di peringkat 11, sementara di ASEAN peringkat ke-4. Akan tetapi, dalam jumlah paten, Indonesia merupakan 
pendaftar paten domestik tertinggi di ASEAN dengan 2.954 paten terdaftar di tahun 2018. Namun jumlah tersebut masih jauh dari negara China, Korea, dan negara maju lainnya (Risbang Kemenristek BRIN, 2019). Untuk peringkat dunia, dalam data di website resmi World Bank (World Bank, n.d.), Indonesia turun 40 peringkat untuk FDI dan transfer teknologi dari 2007 ke 2017. Peringkat terakhirnya adalah 44 dari 137 negara pada 2017. Jauh tertinggal di bandingkan negara tetangga Singapura (peringkat 2) dan Malaysia (peringkat 13).

Masalah ini diungkapkan dalam tulisan Pramisti (2016) disebabkan oleh persoalan-persoalan klasik yakni minimnya kualitas dan kuantitas SDM iptek dan SDM pendukung, minimnya kontribusi sektor swasta dalam mendorong perbaikan produk riset, dan terbatasnya anggaran riset di Indonesia. Persoalan anggaran masih menjadi sorotan penting LPNK Ristek saat ini, khususnya terkait alokasi anggaran yang sangat minim dan pola manajemen pendanaan litbang yang masih kaku (Ariana et al., 2014; Asmara, 2016; Brodjonegoro \& Greene, 2014; Triyono et al., 2020). Anggaran litbang nasional Indonesia sebesar 0,28\% dari Produk Domestik Bruto (PDB) di tahun 2018 (Suranto, 2019), berada di bawah negara-negara Asia Tenggara. Hal ini berakibat pada minimnya keluaran litbang dari LPNK Ristek yang dapat dipasarkan.

Secara Global, menurut World Intellectual Property Organization (WIPO) (2011), transfer teknologi adalah subjek luas yang terbuka untuk didiskusikan dari beberapa sudut pandang. Sebagian besar perdebatan difokuskan pada penyediaan fleksibilitas untuk memungkinkan negara berkembang mendapatkan keuntungan baik komersil maupun non komersil dari teknologi yang dihasilkan oleh negara maju. Upaya tersebut harus dicapai melalui kerjasama langsung antara World Trade Organisation (WTO) dan WIPO. Article 66.2 dalam TRIPS Agreement (1994) yang merupakan perjanjian hukum internasional antara anggota WTO dalam Kekayaan Intelektual dan mengatur transfer teknologi dari negara maju ke negara berkembang (United Nations, 2010). Perjanjian tersebut menetapkan kewajiban bagi negara maju untuk memberikan insentif kepada perusahaan mereka agar mempromosikan transfer teknologi ke negara berkembang sehingga memungkinkan negara-negara tersebut untuk menciptakan basis teknologinya sendiri. Negara berkembang tidak akan berada dalam posisi mendapatkan keuntungan penuh dari transfer teknologi jika mereka masih mengalami masalah dalam mengelola transaksi ini (Correa, 2015).

Di Indonesia, kebijakan transfer teknologi menjadi isu klasik mengingat kontribusi LPNK Ristek masih rendah sejak era orde baru hingga saat ini. Berdasar uraian singkat tersebut, isu kebijakan transfer teknologi di Indonesia terkait erat dengan minimnya kontribusi LPNK Ristek dalam melakukan hilirisasi hasil kegiatan litbang ke para penggunanya. Salah satu alternatif kebijakan yang menjadi terobosan untuk meminimalisir persoalan transfer teknologi dengan mencermati berbagai isu yakni kebijakan Technology Transfer Office (TTO). Kebijakan ini cukup populer diterapkan di negara maju dalam menghilirkan produk hasil litbang ke industri dan pengguna, namun jarang dilakukan di negara berkembang.

TTO sudah diakui di negara-negara maju sebagai mekanisme formal dan esensial untuk mengoperasikan transaksi transfer teknologi. Amerika, Australia, Kanada, Jepang, Inggris, dan negara maju lainnya serta India sebagai negara berkembang sudah menerapkan TTO sebagai kebijakan transfer teknologi yang efektif (Chakroun, 2017). Jika secara tradisional, misi TTO adalah untuk menghubungkan antara akademisi dan industri, dalam kaitannya dengan pasal 66.2 dan 67 TRIPS Agreement (1994), TTO juga memainkan peran perantara utama antara produsen dan penerima teknologi. Misi utama TTO adalah mengelola proses transfer teknologi agar sesuai dengan strategi inovasi. Oleh karena itu, menyiapkan TTO harus dipertimbangkan sebagai bagian dari strategi yang komprehensif untuk mendorong perkembangan teknologi, melaksanakan proses transfer teknologi, sehingga mampu mendapatkan manfaat secara optimal (Chakroun, 2017).

Studi ini bertujuan untuk menjelaskan berbagai kebijakan saat ini yang menghambat LPNK Ristek dalam mendorong transfer teknologi dilihat dari isu pendanaan, SDM, dan kelembagaan kemudian memberikan penjelasan mengenai desain kebijakan TTO yang sesuai sebagai alternatif kebijakan dalam mendorong transfer teknologi di LPNK Ristek. 
Studi ini mengajukan dua pertanyaan utama yang hendak dijawab. Pertanyaan penelitian ini sebagai berikut:

1) Apa saja yang menghambat LPNK Ristek dalam mendorong transfer teknologi dilihat dari isu pendanaan, SDM, dan kelembagaan?

2) Bagaimana desain dari kebijakan TTO yang sesuai sebagai alternatif kebijakan dalam mendorong transfer teknologi di LPNK Ristek?

\section{Metode}

Pendekatan studi ini adalah kualitatif dengan metode desk research. Studi ini berupaya menggali data dari berbagai sumber sebagai data sekunder (Johnston, 2014), yang merupakan sumber data utama kajian dengan metode desk research atau Secondary Data Analysis (SDA) dengan data kualitatif. SDA dengan data kualitatif dilakukan dengan melakukan kajian dimana pengumpulan data dari studi sebelumnya dilakukan untuk mengeksplorasi pertanyaan penelitian baru atau strategi analisis yang bukan merupakan bagian dari analisis primer (Ruggiano \& Perry, 2019). Menurut Mauthner et al (1998) dalam (Ruggiano \& Perry, 2019) proses re-analisa data bisa berbeda dibandingkan dengan peneliti awal yang pertama kali mengumpulkan data karena bisa lebih objektif dalam melihat data yang ada.

Metode dalam kajian ini dengan mengumpulkan data sekunder, menganalisis, serta menafsirkannya sesuai dengan topik studi (Creswell, 2014). Pemanfaatan data sekunder dalam desk research relevan dengan kondisi saat ini yang berada di era digital dengan segala kemajuan teknologinya, sehingga metode desk research memberi kenyamanan secara aktual kepada peneliti. Data sekunder yang digunakan berupa buku, artikel jurnal, artikel prosiding, dokumen perundang-undangan, serta dokumen terkait topik utama yaitu TTO.

Teknik analisis dalam studi ini dilakukan dengan mengacu pada konsep desain kebijakan makro (Birkland, 2001, 2015). Desain ini merupakan bentuk dari kebijakan yang berangkat dari isu minimnya hilirisasi atau komersialisasi hasil litbang berikut kebijakan transfer teknologi yang saat ini sudah ada (existing policies) dan kemudian mengusulkan alternatif kebijakan baru untuk menggantikan kebijakan yang lama. Secara sederhana, Birkland $(2001,2015)$ memberikan lima elemen dalam mendesain kebijakan makro, dimana pada tulisan terbarunya (Birkland, 2015) terdapat tambahan satu elemen penentuan masalah di dalam penyusunan desain makro kebijakan. Elemen desain kebijakan studi tertuang dalam tabel 1.

Tabel 1. Elemen-Elemen Desain Kebijakan.

\begin{tabular}{ll}
\multicolumn{1}{c}{ Elemen } & \multicolumn{1}{c}{ Pertanyaan untuk Dijawab } \\
Masalah/Isu & $\begin{array}{l}\text { Apa yang menjadi masalah dalam kebijakan? Apa ada bukti yang kuat } \\
\text { jika itu adalah masalah kebijakan? }\end{array}$ \\
\hline Tujuan Kebijakan & $\begin{array}{l}\text { Apa tujuan dari sebuah kebijakan? Apakah untuk mengurangi, } \\
\text { menyelesaikan, atau usaha agar masalah tersebut tidak bertambah? }\end{array}$ \\
\hline Model Kausal & $\begin{array}{l}\text { Bagaimana kita mengetahui bahwa jika kita melakukan X akan } \\
\text { menghasilkan Y? Bagaimana kita mencari tahu hal tersebut? }\end{array}$ \\
\hline Alat atau Instrumen Kebijakan & $\begin{array}{l}\text { Apa alat atau instrumen kebijakan yang dapat digunakan untuk } \\
\text { menempatkan kebijakan yang berpengaruh? Apakah mereka } \\
\text { bergantung pada insentif, persuasi, atau informasi? Pembangunan } \\
\text { kapasitas? }\end{array}$ \\
\hline Target Kebijakan & $\begin{array}{l}\text { Perilaku siapa yang disarankan untuk diubah? Apakah pilihan desain } \\
\text { diprediksi pada pembangunan konstruksi sosial dari populasi target? }\end{array}$ \\
\hline Implementasi Kebijakan & $\begin{array}{l}\text { Bagaimana program akan diimplementasikan? Siapa yang akan } \\
\text { melakukan lay out sistem implementasi? Apakah dan mengapa desain } \\
\text { top-down atau bottom-up yang dipilih? }\end{array}$ \\
\hline
\end{tabular}

Sumber: Birkland (2001, 2015); data yang diolah 


\section{Hasil Dan Pembahasan}

\section{III.A. Kebijakan yang Sudah Ada}

Ada beberapa isu kebijakan yang sudah dijalankan dalam mendorong transfer teknologi dari LPNK Ristek ke pengguna (industri, pemerintah, dan masyarakat). Isu pertama terkait dengan pendanaan. Pengelolaan dana litbang dan transfer teknologi saat ini dilakukan melalui skema PNBP, di mana skema ini diatur di dalam Undang-Undang Nomor 20 Tahun 1997 tentang Penerimaan Negara Bukan Pajak (PNBP). Salah satu penyebab kurang optimalnya hilirisasi dalam LPNK Ristek adalah belum jelasnya mekanisme insentif yang diberikan kepada peneliti. Kondisi yang terjadi saat ini ialah LPNK Ristek tidak bisa langsung menggunakan dana yang diperoleh dari penjualan Kekayaan Intelektual (KI) karena dana yang diperoleh bersumber dari pengelolaan dana pemerintah (APBN). Akibatnya, setiap keuntungan yang diperoleh oleh LPNK Ristek masuk ke dalam kategori PNBP sehingga keuntungan yang didapatkan dari komersialisasi KI harus disetorkan kepada negara. Hal ini menyebabkan LPNK Ristek mengalami kesulitan finansial dan berimbas pada hasil KI yang diproduksi oleh LPNK Ristek (World Bank \& Kementerian Ristekdikti, 2017). Unit-unit kerja yang berfungsi dalam melakukan transfer teknologi di LPNK Ristek, seperti Pusat Pemanfaatan Inovasi dan Iptek (dulu bernama Pusat Inovasi) LIPI dan Pusat Pelayanan Iptek BPPT menggunakan mekanisme PNBP untuk menjual jasa atau hasil litbang. Nyatanya tidaklah berjalan karena dana pemasukan penjualan jasa dan hasil litbang tersebut harus disetor ke Direktorat Jenderal Perbendaharaan Negara, Kementerian Keuangan dan tidak dapat langsung dikelola untuk aktivitas litbang dan diseminasi hasil litbang.

Isu kedua yakni terkait dengan kapasitas dan kapabilitas SDM iptek seperti peneliti, perekayasa, dan SDM pendukung lainnya dalam menjalankan fungsi litbang dan transfer teknologi. Selama ini, pemerintah telah menyediakan beasiswa dan bantuan pendanaan lainnya dari Kemenristek/BRIN baik murni dari APBN maupun pinjaman dari World Bank. Beasiswa diberikan baik dalam bentuk program degree (sekolah lanjut) maupun program non-degree (pelatihan, seminar, workshop, dan lainnya). Bantuan ini sering disebut pendanaan SDM Iptek dan Riset-Pro. Beasiswa ini menjadi instrumen untuk melakukan fasilitasi dan koordinasi dalam rangka mendukung penguatan Sistem Inovasi Nasional (SINas) dan Sistem Inovasi Daerah (SIDa). Pada awalnya, dengan diterbitkannya Peraturan Menteri Negara Riset dan Teknologi Nomor 01/M/PER/VI/2009 tentang Pemberian Beasiswa Program Pascasarjana, Kementerian Riset dan Teknologi membatasi pemberian beasiswa hanya kepada para peneliti yang berada di lingkungan Kemenristek dan LPNK Ristek dan tidak dijelaskan jenis program yang dapat dilaksanakan (Kementerian Ristekdikti, 2017a). Namun demikian, program beasiswa yang disediakan tersebut masih memiliki banyak permasalahan.

Pertama, penanggung jawab program belum melaksanakan tugas dan tanggung jawabnya sesuai pedoman. Kedua, perguruan tinggi penerima belum melaksanakan tugas dan tanggung jawabnya sesuai pedoman. Ketiga, jasa giro di rekening penampung tidak di setor ke Kas Negara, dan beberapa masalah lainnya (Hardi, 2017).

Isu ketiga yakni berkaitan dengan kelembagaan untuk ekosistem aktivitas litbang dan transfer teknologi. Mekanisme kelembagaan ini dilakukan melalui pembentukan dan pembangunan STP sebagai fasilitator pendukung kolaborasi antara penyedia produk litbang (LPNK Ristek) dengan para penggunanya (industri, pemerintah, dan masyarakat). Namun demikian, mekanisme kelembagaan STP saat ini sarat dengan beberapa isu, misalnya dominasi egosektoral di kelembagaan STP, lemahnya pengawasan, evaluasi, dan perencanaan strategis STP (Asmara, Oktaviyanti, Alamsyah, \& Zulhamdani, 2016; Muhammad, Faisal, \& Anindito, 2017). Dari sisi kuantitas, rencana pembangunan STP sebanyak 100 unit dalam Rencana Pembangunan Jangka Menengah Nasional (RPJMN) Tahun 2014-2019 nyatanya tereduksi hingga 22 unit. Dari sisi kualitas, desain STP saat ini tidak benar-benar mencerminkan fungsi STP sebagaimana konsep yang ada, namun hanya merupakan "perubahan nomenklatur nama" dimana hal tersebut mencakup fungsi-fungsi teknis seperti diseminasi dan pembelajaran iptek dan tidak mencerminkan adanya komersialisasi dan transfer iptek antar lembaga litbang dengan pihak industri. Hal ini diperburuk dengan minimnya 
SDM pengelola, anggaran terbatas dan kaku, serta kurangnya koordinasi dalam pelaksanaan, sehingga interaksi antara industri, lembaga akademisi masih belum terlihat riil, dan regulasi yang ada masih terbatas (Asmara et al., 2016).

\section{III.B. Desain Baru Kebijakan Transfer Teknologi}

Mengacu pada studi yang dilakukan oleh Rachmawati et al. (2014) bahwa pusat penelitian yang memiliki strategi dan manajemen litbang yang fleksibel terhadap anggaran kegiatan litbang serta dekat dengan kebutuhan pasar atau penggunanya lebih menghasilkan produk yang siap dikomersialisasikan. Hal ini sesuai dengan temuan Surminah et al. (2004) dan Surminah (2004) mengenai model komunikasi dan pola komersialisasi hasil litbang di LIPI dimana interaksi antara pengguna dengan peneliti menjadi faktor esensial untuk mendukung keberhasilan strategi komersialisasi yakni melalui kebijakan TTO. Kebijakan TTO menjadi populer di negara-negara maju, namun belum banyak diterapkan di negara berkembang, termasuk di Indonesia.

\section{III.B.1. Definisi dan Tujuan Kebijakan Transfer Teknologi}

Transfer teknologi memiliki beragam definisi baik dari pakar, lembaga, maupun sumber kredibel lainnya. Peneliti (penulis) berupaya merangkum dan memberikan definisi tersendiri terhadap konsep transfer teknologi. Definisi ini merujuk dari dua sumber United Nations Conference on Trade and Development (UNCTAD) (2014) dan Undang-Undang Republik Indonesia Nomor 11 Tahun 2019 Tentang Sistem Nasional Ilmu Pengetahuan Dan Teknologi. Transfer teknologi adalah upaya timbal balik yang dilakukan oleh lembaga litbang, industri, dan organisasi lain terkait dalam memindahkan sebagian atau semua teknologi, kemampuan teknologi, dan/atau kandungan teknologi di dalamnya yang dianggap baru oleh salah satu pihak atau lebih dengan cara melakukan transaksi ekonomi atau non-ekonomi dengan tujuan tertentu yang telah disepakati diantara pihak terkait.

Kebijakan transfer teknologi bertujuan untuk meningkatkan produktivitas kegiatan litbang di LPNK Ristek serta mendekatkan LPNK Ristek dengan penggunanya (industri, masyarakat, pemerintah). Tujuan lainnya menurut Undang-undang (UU) Nomor 11 Tahun 2019 tentang tentang Sistem Nasional Ilmu Pengetahuan dan Teknologi bahwa alih teknologi melalui investasi badan usaha dari negara-negara maju berpotensi menghasilkan dampak ekonomi yang besar apabila kegiatan tersebut dapat dikaitkan dengan jaringan produsen domestik dalam rantai pertambahan nilai produksi. Di sisi lain, menurut ketentuan Pasal 4 Peraturan Pemerintah (PP) Nomor 20 tahun 2005 tentang Alih Teknologi Kekayaan Intelektual serta Hasil Kegiatan Penelitian dan Pengembangan oleh Perguruan Tinggi dan Lembaga Penelitian dan Pengembangan dinyatakan bahwa tujuan alih teknologi yakni menyebarluaskan iptek serta meningkatkan kemampuan masyarakat dalam memanfaatkan iptek guna kepentingan masyarakat dan negara. Oleh karena itu, diperlukan model transfer teknologi yang mampu mewujudkan tujuan alih teknologi yang diuraikan dalam kedua regulasi diatas yakni mampu meningkatkan kemampuan masyarakat maupun menghasilkan dampak ekonomi bagi negara. Model transfer teknologi yang dapat dijadikan alternatif untuk mewujudkan kedua hal tersebut adalah TTO yang dapat menjadi bagian dari ekosistem inovasi.

Transfer teknologi memiliki beragam definisi baik dari pakar, lembaga, maupun sumber kredibel lainnya. Peneliti (penulis) berupaya merangkum dan memberikan definisi tersendiri terhadap konsep transfer teknologi. Definisi ini merujuk dari dua sumber United Nations Conference on Trade and Development (UNCTAD) (2014) dan Undang-Undang Republik Indonesia Nomor 11 Tahun 2019 Tentang Sistem Nasional Ilmu Pengetahuan Dan Teknologi. Transfer teknologi adalah upaya timbal balik yang dilakukan oleh lembaga litbang, industri, dan organisasi lain terkait dalam memindahkan sebagian atau semua teknologi, kemampuan teknologi, dan/atau kandungan teknologi di dalamnya yang dianggap baru oleh salah satu pihak atau lebih dengan cara melakukan transaksi ekonomi atau non-ekonomi dengan tujuan tertentu yang telah disepakati diantara pihak terkait. 
Kebijakan transfer teknologi bertujuan untuk meningkatkan produktivitas kegiatan litbang di LPNK Ristek serta mendekatkan LPNK Ristek dengan penggunanya (industri, masyarakat, pemerintah). Tujuan lainnya menurut Undang-undang (UU) Nomor 11 Tahun 2019 tentang tentang Sistem Nasional Ilmu Pengetahuan dan Teknologi bahwa alih teknologi melalui investasi badan usaha dari negara-negara maju berpotensi menghasilkan dampak ekonomi yang besar apabila kegiatan tersebut dapat dikaitkan dengan jaringan produsen domestik dalam rantai pertambahan nilai produksi. Di sisi lain, menurut ketentuan Pasal 4 Peraturan Pemerintah (PP) Nomor 20 tahun 2005 tentang Alih Teknologi Kekayaan Intelektual serta Hasil Kegiatan Penelitian dan Pengembangan oleh Perguruan Tinggi dan Lembaga Penelitian dan Pengembangan dinyatakan bahwa tujuan alih teknologi yakni menyebarluaskan iptek serta meningkatkan kemampuan masyarakat dalam memanfaatkan iptek guna kepentingan masyarakat dan negara. Oleh karena itu, diperlukan model transfer teknologi yang mampu mewujudkan tujuan alih teknologi yang diuraikan dalam kedua regulasi diatas yakni mampu meningkatkan kemampuan masyarakat maupun menghasilkan dampak ekonomi bagi negara. Model transfer teknologi yang dapat dijadikan alternatif untuk mewujudkan kedua hal tersebut adalah TTO yang dapat menjadi bagian dari ekosistem inovasi.

III.B.2. Penyebab Persoalan Transfer Teknologi

Berdasar temuan di awal, tujuan transfer teknologi yang terjadi di LPNK Ristek terhambat oleh tiga persoalan utama yaitu persoalan pendanaan yang bersumber dari APBN dan sistem keuangan negara yang cenderung kaku dan menghambat aktivitas litbang dan transfer teknologi, keterbatasan kualifikasi SDM, serta kelembagaan organisasi iptek yang tidak mendukung aktivitas litbang dan transfer teknologi.

III.B.3. Kebijakan Technology Transfer Office dan Instrumen Kebijakannya Untuk meminimalisir ketiga persoalan transfer teknologi sebagaimana diuraikan sebelumnya, butuh suatu terobosan kebijakan baru beserta instrumen yang sesuai dengan kondisi riil di lapangan. Studi ini memberikan alternatif kebijakan TTO. TTO adalah organisasi yang menjadi sarana proses transfer teknologi dengan cara memfasilitasi proses riset dengan inovasi (Kementerian Ristekdikti, 2017b). Ada empat prasyarat yang harus dipenuhi untuk mendukung keberhasilan TTO. Prasyarat tersebut antara lain process, people, prototype, dan patent budget (EU-IndonesiaTCF, 2017).

Peran TTO lebih jelasnya yakni: (a) membangun hubungan dengan industri dan masyarakat; (b) mencari dan mendapatkan dukungan pendanaan baru dari penelitian yang disponsori atau jasa konsultasi; (c) memberikan bantuan kepada semua bidang yang terkait dengan kewirausahaan dan kekayaan intelektual; (d) memfasilitasi pembentukan perusahaan dengan memanfaatkan teknologi Public Research Office (PRO) (start-up) dan/atau universitas (spin-off) untuk meningkatkan prospek pengembangan lebih lanjut; dan (e) menghasilkan royalti serta berkolaborasi dengan mitra PRO (World Bank \& Kementerian Ristekdikti, 2017).

TTO memiliki tiga fungsi utama dalam menjalankan kegiatannya, yaitu fungsi filling, licensing, dan marketing (World Bank \& Kementerian Ristekdikti, 2017). Dalam fungsi filling, TTO berperan sebagai pengelola KI dari berbagai penemuan serta invensi dan inovasi yang terdapat pada lembaga litbang. Fungsi filling dilakukan dengan mengumpulkan riset-riset dari lembaga penelitian, kemudian melakukan evaluasi atau inovasi. Lalu, fungsi marketing, TTO berperan sebagai garda terdepan dalam interaksi dengan industri dan masyarakat. TTO berperan memasarkan produk-produk yang dimiliki oleh lembaga pemerintahan yang menaungi instansi TTO tersebut. TTO diharapkan mampu berhadapan dengan pihak di luar lembaga pemerintah, sehingga masyarakat dan industri mendapat informasi dari paten-paten yang terdapat pada lembaga pemerintah. Kemudian, fungsi licensing merupakan tindak lanjut dari dua fungsi sebelumnya (filling dan marketing). Jika berhasil menjual paten yang dapat digunakan oleh industri, TTO bertindak sebagai negosiator antara lembaga penelitian dan industri dalam proses lisensi paten sebagai tujuan utama dari hilirisasi hasil iptek. 
Salamon dan Lund dalam Birkland (2001, 2015) mengemukakan bahwa setiap kebijakan di setiap negara memiliki karakteristik tertentu yang menjadi pembeda dengan lainnya. Untuk itu instrumen kebijakan sebaiknya terdiri dari empat intrumen utama, yakni (1) dasar dari aktivitas pemerintah yang terlibat di dalamnya, (2) struktur sistem penyampaian, (3) derajat sentralisasi, dan (4) derajat automisasi. Keempat hal tersebut menjadi dasar bagi pemilihan instrumen kebijakan TTO di Indonesia. Penjelasan masing-masing instrumen sebagai berikut.

Instrumen pertama, dasar dari aktivitas pemerintah yang terlibat di dalamnya. Pemerintah Indonesia melalui Kemenristek/BRIN terlibat langsung dalam Kebijakan TTO yang akan dijalankan, Alat atau instrumen kebijakan yang dapat digunakan antara lain (1) pendanaan TTO melalui bantuan hibah (grant), subsidi dan penyediaan barang dan jasa publik dengan klasifikasi khusus; (2) peningkatan kualifikasi dan profesionalitas SDM TTO melalui sistem rekruitmen terbuka yang memberi kesempatan kepada profesional di luar Aparatur Sipil Negara (ASN), pelatihan dan magang di industri, serta perluasan jaringan antar SDM TTO dan lingkungan eksternalnya; dan (3) membentuk ekosistem kelembagaan TTO dengan memberikan desain struktur organisasi melalui pola Badan Layanan Umum (BLU) kepada lembaga TTO baru untuk dapat menghasilkan profit bagi internal organisasi sehingga tidak tergantung pada APBN seperti halnya mekanisme PNBP. Untuk landasan TTO dan mekanisme kelembagaan BLU, dapat merujuk beberapa peraturan pemerintah (Peraturan Pemerintah Republik Indonesia Nomor 20 Tahun 2005 Tentang Alih Teknologi Kekayaan Intelektual Serta Hasil Kegiatan Penelitian Dan Pengembangan Oleh Perguruan Tinggi Dan Lembaga Penelitian Dan Pengembangan, 2015; Peraturan Pemerintah Republik Indonesia Nomor 74 Tahun 2012 Tentang Perubahan Atas Peraturan Pemerintah Nomor 23 Tahun 2005 Tentang Pengelolaan Keuangan Badan Layanan Umum, 2012).

Instrumen kedua, struktur sistem penyampaian. Ketiga mekanisme yang dijelaskan pada instrumen pertama membutuhkan instrumen lain untuk men-deliver programprogram tersebut agar menjadi lebih nyata. Salamon dan Lund dalam Birkland (2001, 2015) menyatakan, sistem mekanisme penyampaian instrumen kebijakan bisa dilakukan jika pemerintah terlibat langsung ke kelompok sasaran kebijakan, dan dapat dilakukan secara tidak langsung jika pemerintah melibatkan pihak lain untuk menyampaikan instrumen kebijakan tersebut ke kelompok sasaran.

Instrumen ketiga, derajat sentralisasi. Semakin dekat mekanisme penyampaian instrumen kebijakan dari pemerintah ke kelompok kebijakan, maka semakin tersentral kebijakan tersebut, dan sebaliknya (Salamon dan Lund dalam Birkland, [2001, 2015]). Begitu pula mekanisme instrumen kebijakan pendanaan dan SDM di TTO, keduanya dapat memiliki derajat sentralisasi tergantung kebutuhan dari penerima kebijakan dan kepentingan Kemenristek/BRIN. TTO akan lebih terikat pada mekanisme tersentral karena segala program, pelaksana dan pertanggungjawaban berasal dari satu instansi pemerintah yang sama yaitu Kemenristek/BRIN. Namun sebaliknya, TTO akan menjadi lembaga fleksibel jika program, pelaksana, dan pertanggungjawaban dimainkan oleh aktor berbeda sehingga ada ruang untuk menjalankan hal-hal di luar kendali penuh dari tiap aktor tersebut.

Mekanisme kelembagaan TTO dengan Badan Layanan Umum (BLU) merupakan sistem penyampaian kebijakan pemerintah gabungan langsung dan tidak langsung. Secara langsung dikarenakan BLU terikat pada Peraturan Pemerintah Republik Indonesia Nomor 74 Tahun 2012 tentang Perubahan Atas Peraturan Pemerintah Nomor 23 Tahun 2005 tentang Pengelolaan Keuangan BLU, peraturan kepemilikan aset negara, aturan kepegawaian negara, aturan keuangan negara, dan aturan lainnya. Dikatakan tidak langsung karena karakter lembaga semi-otonom BLU dapat mencari sumber penghasilan sendiri dan juga merekrut pegawai yang digaji dari sumber pemasukan organisasi BLU yang berasal dari sumber non-APBN.

Instrumen keempat, derajat automisasi. Derajat automisasi digunakan ketika program-program pemerintah memerlukan tindakan administratif secara detail (Salamon dan Lund dalam Birkland, [2001, 2015]). Dari mekanisme pendanaan, SDM, dan kelembagaan BLU, maka diharapkan instrumen kebijakan TTO dapat mendorong secara otomatis kelompok sasaran tersebut agar lebih pro-aktif dalam merespons kebijakan dan menjalankannya. Selain itu, pihak-pihak yang berada di luar TTO 
(pihak-pihak yang bukan merupakan SDM Iptek dan Pendukung Iptek di lingkungan Kemenristek/BRIN dan LPNK terkaitnya), dan memiliki kepentingan bisa berinisiatif agar TTO dapat menjalankan fungsinya dengan baik. Semisal pada tingkat hilirisasi, ada pihak industri dan kalangan pebisnis yang menjadi pengguna hasil-hasil riset.

\section{III.B.4. Target Kebijakan Technology Transfer Office}

Target kebijakan dari TTO meliputi perilaku yang diubah, target langsung, dan tidak langsung, dan konstruksi sosial kelompok sasaran. Target perilaku yang diubah ialah pola aktivitas litbang di LPNK Ristek agar lebih berorientasi pada produk-produk yang dapat dipasarkan ke industri dan ramah pengguna. Tentu pola ini akan mengubah secara sistemik mulai dari jenis rencana riset, aktivitas SDM iptek, mekanisme pengelolaan pendanaan, bentuk diseminasi hasil litbang, manajemen rekruitmen dan karir SDM iptek. Bagi industri, pola kerja yang selama ini pasif dan menunggu hasil litbang pemerintah, berubah aktif sebagai pemberi masukan dan mitra kerja dari LPNK Ristek. Kebijakan TTO memiliki dua target yakni aktor utama (target langsung) dan aktor pendukung (target tidak langsung) dari pelaksanaan kebijakan transfer teknologi. Adapun penjabaran dari peran setiap target tersebut terjabarkan dalam Tabel 2 berikut ini.

Tabel 2. Target Langsung dan Tidak Langsung dari Kebijakan TTO

\begin{tabular}{|c|c|c|c|}
\hline Target Langsung & Peran & Target Tidak Langsung & Peran \\
\hline $\begin{array}{l}\text { LPNK Ristek (LIPI, BPPT, } \\
\text { BATAN, LAPAN) }\end{array}$ & $\begin{array}{l}\text { penghasil dan } \\
\text { penyedia produk- } \\
\text { produk litbang }\end{array}$ & Perguruan tinggi & $\begin{array}{lr}\text { Mitra LPNK } & \text { Ristek } \\
\text { dalam menghasilkan } \\
\text { produk-produk } & \text { litbang } \\
\text { agar hasilnya } & \text { dapat } \\
\text { lebih diterapkan } & \end{array}$ \\
\hline $\begin{array}{l}\text { Industri kecil, menengah, } \\
\text { besar baik nasional } \\
\text { maupun asing (termasuk } \\
\text { industri jasa, manufaktur, } \\
\text { dan kreatif) Masyarakat } \\
\text { individumaupun komunitas }\end{array}$ & $\begin{array}{l}\text { pengguna produk- } \\
\text { produk litbang } \\
\text { sekaligus inisiator ide } \\
\text { kebaruan pengguna } \\
\text { produk-produk litbang } \\
\text { dan inisiator ide } \\
\text { kebaruan }\end{array}$ & $\begin{array}{l}\text { Kementerian Hukum } \\
\text { dan HAM, Kementerian } \\
\text { Keuangan, Kementerian } \\
\text { Koordinator Bidang } \\
\text { P e r e o n o m i a n, } \\
\text { pemerintah daerah dan } \\
\text { agen-agen pemerintah } \\
\text { Media Massa }\end{array}$ & $\begin{array}{l}\text { Fasilitator dan regulator } \\
\text { terkait program- } \\
\text { program pemerintah } \\
\text { secara umum yang } \\
\text { mendukung aktivitas } \\
\text { kelitbangan (pola } \\
\text { pendanaan, kekayaan } \\
\text { intelektual, dan lainnya) }\end{array}$ \\
\hline $\begin{array}{l}\text { Kemenristek/BRIN dan } \\
\text { Kementerian Perindustrian }\end{array}$ & $\begin{array}{l}\text { pengguna produk- } \\
\text { produk litbang } \\
\text { dan fasilitator dan } \\
\text { koordinator terkait } \\
\text { program diseminasi } \\
\text { dan komersialisasi } \\
\text { hasil litbang serta } \\
\text { regulator yang dengan } \\
\text { aktivitas kelitbangan. }\end{array}$ & $\begin{array}{l}\text { Bank dan lembaga } \\
\text { finansial lainnya }\end{array}$ & $\begin{array}{lr}\text { Pemberi } & \text { bantuan } \\
\text { dana untuk } & \text { aktivitas } \\
\text { kelitbangan secara } & \text { smum dan spesifik. }\end{array}$ \\
\hline $\begin{array}{l}\text { Organisasi non-pemerintah } \\
\text { lainnya }\end{array}$ & $\begin{array}{l}\text { pengguna produk- } \\
\text { produk litbang dan } \\
\text { inisiator ide kebaruan }\end{array}$ & $\begin{array}{l}\text { Masyarakat baik individu } \\
\text { maupun komunitas }\end{array}$ & $\begin{array}{l}\text { Sebagai pendukung } \\
\text { iklim kondusif dalam } \\
\text { proses komersialisasi } \\
\text { dan hilirisasi hasil } \\
\text { litbang }\end{array}$ \\
\hline
\end{tabular}

Sumber: Hasil Penelitian. Data diolah (2021)

Kebijakan TTO tidak melahirkan bentuk baru dari konstruksi sosial - kelompok sasaran, karena pada dasarnya kelompok sasaran kebijakan TTO ialah untuk menjalankan fungsi masing-masing dengan baik. Kelompok sasaran tersebut membutuhkan kejelasan hasil kegiatan litbang serta peran koordinator dan penanggung jawab dari kegiatan transfer teknologi yang dijalankan oleh masingmasing LPNK Ristek.

TTO merupakan bagian dari pembentukan desain kebijakan baru yang berfungsi untuk mengoptimalkan hubungan lembaga litbang dan industri serta meningkatkan produktivitas lembaga litbang. Hal terpenting yang harus dipahami ialah TTO bukan lembaga yang sama sekali lepas dari pemerintah, namun merupakan pengembangan satuan kerja dari LPNK Ristek yang mana sedikit-banyak juga akan mempengaruhi konstruksi sosial dari LPNK Ristek itu sendiri. Konstruksi sosial merupakan perubahan 
minor pada LPNK Ristek yang sebagian unit kerjanya berubah menjadi TTO dengan mekanisme BLU. Kondisi ini mengakibatkan LPNK Ristek sebagai kelompok sasaran utama harus mengalami perubahan kelembagaan sehingga juga akan berpengaruh pada tatanan sosial (perilaku, motivasi, nilai) pegawai dan para profesional untuk bekerja sama menjalankan fungsi TTO.

III.B.5. Rancangan Implementasi Kebijakan Technology Transfer Office

Dalam mendesain kebijakan TTO ada beberapa hal yang perlu dibahas, yakni rencana implementasi, siapa yang mendesain sekuensi kebijakan, dan model implementasi kebijakan yang dapat digunakan. Artinya, bukan hanya "bagaimana proses implementasi kebijakan TTO di lakukan, namun juga menyajikan hal-hal yang perlu ada saat kebijakan TTO diimplementasikan selanjutnya".

TTO adalah suatu lembaga yang memiliki fungsi utama dalam melakukan alih teknologi. Idealnya, TTO saling bekerja sama dengan STP. Oleh karena itu, sebuah TTO yang ideal harus berjalan sesuai dengan arah kebijakan STP dimana hasil komersialisasinya berupa pengembangan perusahaan rintisan. LPNK Ristek yang berfungsi sebagai riset publik harus memiliki TTO dan bekerja sama dengan STP agar dapat menghilirisasi hasil penelitian yang dilakukan. Oleh karena itu, TTO dapat bersinergi dengan STP dalam berbagai bentuk kelembagaan yang dibutuhkan LPNK. Tentu keduanya harus dapat menyesuaikan dengan arah perkembangan dan penelitian dalam masing-masing LPNK Ristek (World Bank \& Kementerian Ristekdikti, 2017).

Lay out kebijakan TTO harus dapat menjelaskan arah kebijakan dari Kemenristek/ BRIN, LPNK, dan STP karena TTO ke depan dirancang sebagai lembaga yang berada di bawah Kemenristek/BRIN. Artinya, Kemenristek/BRIN sebagai koordinator dan penanggung jawab seluruh TTO yang ada di Indonesia. Hal tersebut diperlukan agar apa yang dilakukan oleh TTO dapat bergerak selaras dengan Kemenristek/BRIN, dan LPNK dalam melaksanakan kegiatan transfer teknologi, baik itu invensi maupun inovasi. Untuk kebijakan TTO sebaiknya di lay out oleh ahli kebijakan publik atau pakar kelembagaan yang paham dan berpengalaman akan ilmu kebijakan/kelembagaan dan kelitbangan.

Secara sederhana, model implementasi kebijakan TTO yang ditawarkan ialah model kebijakan mixed approach antara kebijakan top-down dan botttom-up. Pendekatan top-down merupakan kebijakan yang dilakukan secara linear dari atas ke bawah yaitu dari pihak berwenang (pemerintah) ke kelompok sasaran, sementara pendekatan bottom-up merupakan kebijakan yang dijalankan dari kelompok sasaran yang kemudian dilaporkan kepada pemerintah.

\section{Kesimpulan}

Ada tiga isu utama yang menghambat transfer teknologi di lembaga litbang Indonesia saat ini, yaitu minimnya pendanaan kegiatan litbang, terbatasnya kualitas dan kuantitas SDM iptek dan SDM pedukungnya, serta struktur kelembagaan yang kaku dan menghambat fungsi transfer teknologi. Ketiga isu tersebut telah diupayakan jalan keluarnya oleh Pemerintah Indonesia. Namun, hasil penelusuran berbagai literatur dan analisis peneliti (penulis) memperlihatkan bahwa ketiga upaya kebijakan tersebut belum menunjukkan hasil optimal karena masih terdapat banyak kelemahan dan dinilai belum efektif untuk meminimalisir persoalan transfer teknologi yang dilakukan oleh LPNK Ristek di Indonesia. Oleh karena itu, solusi yang ditawarkan melalui hasil studi ini adalah menerapkan kebijakan Technology Transfer Office (TTO) sebagai alternatif kebijakan transfer teknologi untuk mengatasi hambatan transfer teknologi yang dapat diadposi pemerintah. Studi ini menemukan dan menjelaskan empat instrumen utama sebagai dasar pemilihan desain instrumen kebijakan TTO yaitu; (1) dari aktivitas pemerintah yang terlibat, (2) struktur sistem penyampaian baik langsung atau tidak langsung, (3) derajat sentralisasi, dan (4) derajat automisasi dengan mekanisme pendanaan, SDM, dan kelembagaan berupa Badan Layanan Umum (BLU). 


\section{Ucapan Terima Kasih}

Peneliti mengucapkan terima kasih kepada Pusat Penelitian Kebijakan dan Manajemen Ilmu Pengetahuan, Teknologi, dan Inovasi Lembaga Ilmu Pengetahuan Indonesia (P2KMI LIPI) dan secara khusus kepada Drs. Budi Triyono, M.Si. yang telah mendukung sepenuhnya studi ini.

\section{Daftar Referensi}

Ariana, L., Fizzanty, T., Hermawati, W., Prihadyanti, D., Laili, N., \& Alamsyah, P. (2014). Perilaku Organisasi Litbang dalam Alokasi Anggaran dan Skenario Kebijakan Alokasi Anggaran Litbang Pemerintah (Lemlit X). Jakarta:LIPIPress. http://www. penerbit.lipi.go.id/penerbitan.cgi?daftar\&1431485167\&3441\&\&semua

Asmara, A. Y. (2016). Kontribusi Lembaga Penelitian dan Pengembangan Pemerintah dalam Pembangunan Nasional: Tinjauan Konsep Komersialisasi. Prosiding Seminar Nasional "Kontribusi Akademisi Dalam Pencapaian Pembangunan Berkelanjutan,” 75-83. Malang: Universitas Brawijaya. https://core.ac.uk/ download/pdf/198494296.pdf

Asmara, A. Y., Oktaviyanti, D., Alamsyah, P., \& Zulhamdani, M. (2016). Science-Techno Park and Industrial Policy in Indonesia. Paper in 'Korea and the World Economy XV' Conference to Be Held at Korea Federation of Banks. http://www.akes.or.kr/eng/papers(2016)/F29.pdf

Birkland, T. A. (2001). An Introduction to the Policy Process: Theories, Concepts, and Models of Public Policy Making (1st Ed.). London: M. E. Sharpe. https://rcp.umn.edu/sites/rcp.umn.edu/files/introduction_to_ the_policy_process.pdf

Birkland, T. A. (2015). An Introduction to the Policy Process: Theories, Concepts, and Models of Public Policy Making (3rd Ed.). London: Routledge. https://www.routledge.com/An-Introduction-to-the-PolicyProcess-Theories-Concepts-and-Models-of/Birkland/p/book/9781138495616

Brodjonegoro, S. S., \& Greene, M. P. (2014). Creating an Indonesian Science Fund. https://www.neliti.com/ id/publications/812/creating-an-indonesian-science-fund

Chakroun, N. (2017). Using technology transfer offices to foster technological development: A proposal based on a combination of articles 66.2 and 67 of the TRIPS agreement. The Journal of World Intellectual Property, 20, 103-118. https://doi.org/10.1111/jwip.12077

Correa, C. (2015). Can the TRIPS agreement foster technology transfer to developing countries? In K. E. Maskus \& J. H. Reichman (Eds.), International public goods and transfer of technology under a globalized intellectual property regime. New York: Cambridge University Press. http://kadint.net/ journals n/1430116707.pdf

Creswell, J. W. (2014). Research Design: Qualitative, Quantitative, and Mixed Methods Approaches (4th Ed.). Los Angeles; London; New Dehli; Singapore; Washington DC: Sage Publications. http://www. drbrambedkarcollege.ac.in/sites/default/files/Research-Design_Qualitative-Quantitative-and-MixedMethods-Approaches.pdf

EU-IndonesiaTCF. (2017). Guide to Setting Up Technology Transfer Office.

Gerintya, S. (2017). Kondisi Dunia Penelitian di Indonesia. Retrieved from https://tirto.id/kondisi-duniapenelitian-di-indonesia-cvvj

Hardi, M. (2017). Permasalahan Beasiswa - Inspektorat Jenderal Kemenristekdikti. http://ittama.ristekbrin. go.id/wp-content/uploads/2017/02/PERMASALAHAN-BEASISWA-Bapak-Inspektur-I.pdf

Johnston, M. P. (2014). Secondary Data Analysis: A Method of which the Time Has Come Melissa. Qualitative and Quantitative Methods in Libraries (QQML), 3, 619-626. http://qqmL.net/papers/September_2014_ Issue/336QQML_Journal_2014_Johnston_Sept_619-626.pdf

Kementerian Ristekdikti. (2017a). Pedoman Beasiswa SDM Iptek Kemenristekdikti Tahun 2017. Retrieved from. http://sumberdaya.ristekdikti.go.id/wp-content/uploads/2017/07/Pedoman-Beasiswa-SDMIptek-2017.pdf

Kementerian Ristekdikti. (2017b). Term of Reference Inisiasi Regulasi Terkait Penguatan TTO. Jakarta.

Lakitan, B., Hidayat, D., \& Herlinda, S. (2012). Scientific productivity and the collaboration intensity of Indonesian universities and public R\&D institutions: Are there dependencies on collaborative R\&D with foreign institutions? Technology in Society, 34(3), 227-238. https://doi.org/10.1016/j. techsoc.2012.06.001

Muhammad, N. A., Faisal, A., \& Anindito, I. A. (2017). Studi Pembangunan Science and Technopark (STP) di Indonesia. Jurnal Perencanaan Dan Pembangunan, 1(1), 14-31. https://doi.org/10.36574/jpp.v1i1.6

Oktaviyanti, D., Kusbiantono, Sari, K., Arifin, M., Rahayu, S., \& Asmara, A. Y. (2013). Analisis Perkembangan Kebijakan Ilmu Pengetahuan dan Teknologi di Indonesia dari Era Orde Lama hingga Era Orde Baru Jakarta.http://lipi.go.id/publikasi/1analisis-perkembangan-kebijakan-ilmu-pengetahuan-danteknologi-di-indonesia-dari-era-orde-lama-hingga-era-orde-baru-/16386

Pramisti, N. Q. (2016). Muramnya Wajah Dunia Riset Indonesia. Retrieved from https://tirto.id/muramnyawajah-dunia-riset-indonesia-bsF6

Rachmawati, R., Asmara, A. Y., \& Badriani, M. (2014). Kajian Tata Kelola Pendanaan Riset di LPNK Ristek. Laporan Akhir Kementerian Riset dan Teknologi Sub Kegiatan: RISET-PRO Nomor 09/Kontrak/RisetPro/ D2/AD2-2/IX/2014.

Risbang Kemenristek BRIN. (2019). Indonesia Harus Meningkatkan Produktivitas Paten Jika Ingin Menjadi Negara Maju. Retrieved from https://risbang.ristekbrin.go.id/publikasi/berita-kegiatan/indonesia-harusmeningkatkan-produktivitas-paten-jika-ingin-menjadi-negara-maju/\#: : text="Indonesia merupakan pendaftar paten domestik, paten terdaftar di tahun 2018\%0A

Ruggiano, N., \& Perry, T. E. (2019). Conducting secondary analysis of qualitative data: Should we, can we, and how? Qualitative Social Work, 18(1), 81-97. https://doi.org/https://doi. 
org/10.1177/1473325017700701

Soedarsono, S. (2004). Mengukur Kompetensi Unit Riset. Info Kajian Bappenas, 1(2), 87-96.

Suranto. (2019). GERD Indonesia Mengalami Kenaikan. Retrieved from http://infopublik.id/kategori/ nasional-sosial-budaya/372769/gerd-indonesia-mengalami-kenaikan

Surminah, I. (2004). Pola Komersialisasi Hasil Litbang di LIPI. Warta Kebijakan Iptek Dan Manajemen Litbang, 2, 99-113. http://www.stipmjournal.org/index.php/stipm/article/download/93/pdf

Surminah, I., Pabeta, A. T., \& Soedibyo. (2004). Penelitian tentang Model Komunikasi Komersialisasi Hasil Litbang. Jakarta: Pappiptek-LIPI. https://core.ac.uk/download/pdf/198494296.pdf

TRIPS Agreement. (1994). Marrakesh Agreement Establishing the World Trade Organization, Annex 1C, 1869 U.N.T.S. 299, 33 I.L.M. 1197. Retrieved from Agreement on Trade-Related Aspects of Intellectual Property Rights website: https://www.wto.org/english/docs_e/legal_e/trips_e.htm\#art3

Triyono, B., Hardiyati, R., \& Pradana, A.W. (2020). The Gap Between Program Planning and Implementation: The Case of R\&D Program in Indonesian RPJMN. Journal of STI Policy and Management, 5(2), 137-146 http://dx.doi.org/10.14203/STIPM.2020.285

United Nations. (2010). Training Module on the WTO Agreement on Trade-Related Aspects of Intellectual Property Rights (TRIPS). Retrieved from https://unctad.org/system/files/official-document/ ditctncd20083_en.pdf

United Nations Conference on Trade and Development (UNCTAD). (2014). Transfer of technology and knowledge sharing for development: science, technology and innovation issues for developing countries. In UNCTAD Current studies on science, tecnology and innovation (Vol. 8). Retrieved from UNCTAD/DTL/ STICT/2013/8 https://unctad.org/en/PublicationsLibrary/dtlstict2013d8_en.pdf

World Bank. (n.d.). FDI and Technology Transfer. Retrieved from https://tcdata360.worldbank.org/indicators/ h2b4ffaf7? indicator $=717 \&$ \&viz=line chart\&years $=2007,2017 \% 0$ A

World Bank, \& Kementerian Ristekdikti. (2017). Inisiasi Regulasi Penguatan Technology Transfer Office (Naskah Policy Paper) (pp. 1-56). pp. 1-56.

World Intellectual Property Organization (WIPO). (2011). Transfer of technology in its fourteenth session. SCP/14/4/rev, Geneva, April, 13th. http://www.wipo.int/edocs/mdocs/scp/en/scp_16/scp_14_4_rev. $\mathrm{pdf}$

Zuhal. (2000). Visi Iptek Memasuki Milenium III. Jakarta: UI Press. https://perpustakaan.bsn.go.id/index. php?p=show_detail\&id $=2783$ 